\title{
Effects of interactions between common genetic variants and alcohol consumption on colorectal cancer risk
}

\author{
Nan Song ${ }^{1}$, Aesun Shin ${ }^{1,2,3, *}$, Jae Hwan $\mathrm{Oh}^{4}$ and Jeongseon Kim ${ }^{3, *}$ \\ ${ }^{1}$ Cancer Research Institute, Seoul National University College of Medicine, Seoul, Korea \\ ${ }^{2}$ Department of Preventive Medicine, Seoul National University College of Medicine, Seoul, Korea \\ ${ }^{3}$ Molecular Epidemiology Branch, National Cancer Center, Goyang, Korea \\ ${ }^{4}$ Center for Colorectal Cancer, National Cancer Center, Goyang, Korea \\ *These authors have contributed equally to this work \\ Correspondence to: Aesun Shin, email: shinaesun@snu.ac.kr \\ Jeongseon Kim, email: jskim@ncc.re.kr \\ Keywords: colorectal cancer; gene and environment interaction; single-nucleotide polymorphism; alcohol consumption; case- \\ control study \\ Received: June 01, $2017 \quad$ Accepted: December 28, $2017 \quad$ Published: January 06, 2018 \\ Copyright: Song et al. This is an open-access article distributed under the terms of the Creative Commons Attribution License 3.0 \\ (CC BY 3.0), which permits unrestricted use, distribution, and reproduction in any medium, provided the original author and source \\ are credited.
}

\section{ABSTRACT}

Background: Genome-wide association studies (GWAS) have identified approximately $\mathbf{4 0}$ common genetic loci associated with colorectal cancer risk. To investigate possible gene-environment interactions (GEIs) between GWAS-identified single-nucleotide polymorphisms (SNPs) and alcohol consumption with respect to colorectal cancer, a hospital-based case-control study was conducted.

Results: Higher levels of alcohol consumption as calculated based on a standardized definition of a drink ( 1 drink $=12.5 \mathrm{~g}$ of ethanol) were associated with increased risk of colorectal cancer $(O R=2.47,95 \% \mathrm{CI}=1.62-3.76$ for heavy drinkers $\left[>50 \mathrm{~g} /\right.$ day] compared to never drinkers; $\left.p_{\text {trend }}<0.01\right)$. SNP rs6687758 near the DUSP10 gene at 1q41 had a statistically significant interaction with alcohol consumption in analyses of standardized drinks $\left(p=4.6 \times 10^{-3}\right)$, although this did not surpass the corrected threshold for multiple testing. When stratified by alcohol consumption levels, in an additive model the risk of colorectal cancer associated with the G allele of rs6687758 tended to increase among individuals in the heavier alcohol consumption strata. A statistically significant association between rs6687758 and colorectal cancer risk was observed among moderate alcohol drinkers who consumed between $>12.5$ and $\leq 50 \mathrm{~g}$ of alcohol per day $(\mathrm{OR}=1.46,95 \% \mathrm{CI}=1.01-2.11)$.

Methods: A total of 2,109 subjects (703 colorectal cancer patients and 1,406 healthy controls) were recruited from the Korean National Cancer Center. For genotyping, 30 GWAS-identified SNPs were selected. A logistic regression model was used to evaluate associations of SNPs and alcohol consumption with colorectal cancer risk. We also tested GEIs between SNPs and alcohol consumption using a logistic model with multiplicative interaction terms.

Conclusions: Our results suggest that SNP rs6687758 at 1q41 may interact with alcohol consumption in the etiology of colorectal cancer. 


\section{INTRODUCTION}

Alcoholic beverages are classified as carcinogenic agents with sufficient evidence for colorectal cancer by the International Agency for Research on Cancer [1]. Absorbed alcohol is distributed to colonocytes through the blood stream and metabolized to acetaldehyde, also a known carcinogen, by intestinal microbes [2]. Following alcohol consumption, acetaldehyde accumulated in colonocytes could induce multiple carcinogenic effects, such as DNA damage, excessive cell proliferation of the colonic mucosa, and inhibition of folate absorption [3].

Alcohol-induced carcinogenesis is affected by alcohol-metabolizing enzymes, including alcohol dehydrogenase (ADH), acetaldehyde dehydrogenase (ALDH), and cytochrome P450 2E1 (CYP2E1), and by the methylenetetrahydrofolate reductase (MTHFR) enzyme, which plays a crucial role in folate metabolism [2]. Accordingly, previous studies have commonly focused on $A D H 1 B, A D H 1 C, A L D H 2, C Y P 2 E 1$, and MTHFR genotypes as modifiers of the association between alcohol consumption and risk of alcohol-related cancers, including colorectal cancer [4]. Nevertheless, evidence for gene-environment interaction (GEI) involving alcohol consumption and colorectal carcinogenesis remains inconsistent or inconclusive [4], suggesting the need for more studies on interaction effects between various genetic polymorphisms and alcohol consumption with respect to colorectal cancer risk.

Genome-wide association studies (GWAS) have identified a number of single-nucleotide polymorphisms (SNPs) that may be involved in colorectal cancer susceptibility; however, none are directly involved in the alcohol metabolism pathway. Several studies have investigated possible GEIs between GWAS-identified SNPs and alcohol consumption [5-9]. We hypothesized that colorectal cancer susceptibility SNPs could interact with alcohol consumption to influence the risk of colorectal cancer. To test this hypothesis, we examined associations of alcohol consumption and GWAS-identified colorectal cancer susceptibility SNPs with colorectal cancer risk in a Korean population. Associations were also evaluated after stratification by alcohol consumption levels to understand whether they were modified by alcohol consumption.

\section{RESULTS}

The characteristics of the study participants are shown in Table 1. Among a total of 703 colorectal cancer cases and 1,406 healthy controls, neither average age (56.4 years in cases and 56.0 years in controls) nor the distribution of sex differed, indicating adequate matching. Colorectal cancer cases had higher proportions of participants with a family history of colorectal cancer $(p=0.01)$ or lower education level $(p<0.01)$ and who were unmarried $(p<0.01)$ or did not exercise regularly $(p<0.01)$. Body mass index (BMI) was higher among controls $(p=0.04)$. Neither alcohol consumption nor smoking status differed between colorectal cases and controls. We investigated associations between alcohol consumption factors and colorectal cancer risk (Table 2). Although general alcohol consumption status (ever vs. never) was not statistically associated with colorectal cancer risk, higher levels of alcohol consumption based on standardized drink amounts were associated with increased risk of colorectal cancer $\left(p_{\text {trend }}<0.01\right)$, especially for heavy drinkers compared to never drinkers (odds ratio $(\mathrm{OR})=2.47,95 \%$ confidence interval $(\mathrm{CI})=1.62-3.76)$. Similar associations with colorectal cancer risk were also observed for alcohol consumption levels when categorized by the median $\left(p_{\text {trend }}=0.05\right)$ and by tertiles of intake $\left(p_{\text {trend }}<0.01\right)$; the highest tertiles of alcohol consumption had a statistically significant association with risk of colorectal cancer $(\mathrm{OR}=1.50,95 \% \mathrm{CI}=1.08-2.07)$. When stratified by sex, similar associations were found among men between the higher alcohol consumption categories and increased colorectal cancer risk; these associations were attenuated among women (data not shown).

Among 30 GWAS-identified SNPs, 15 SNPs including rs6687758, rs647161, rs6983267, rs7014346, rs10505477, rs10795668, rs704017, rs11196172, rs174537, rs174550, rs1535, rs4779584, rs10411210, rs961253, and rs2423279 were validated in our study population $(p<0.05$, Supplementary Table 1$)$. Among those SNPs, rs6687758 at 1q41 (intergenic) and rs4813802 at 20 p 12.3 had statistically significant interactions with alcohol consumption based on standardized drink amounts $\left(p_{\text {interaction }}=4.6 \times 10^{-3}\right.$ for $\mathrm{rs} 6687758$ and $p_{\text {interaction }}=0.02$ for rs4813802, Table 3). GEIs with colorectal cancer risk for rs6687758 were also observed with general alcohol consumption status ( $\left.p_{\text {interaction }}=0.02\right)$, alcohol consumption categorized by the median $\left(p_{\text {interaction }}=7.4 \times 10^{-3}\right)$, and by tertiles of intake $\left(p_{\text {interaction }}=3.9 \times 10^{-3}\right)$ (Supplementary Table 2). However, observed GEIs did not surpass the corrected threshold for multiple testing ( $p$-value for Bonferroni correction $<1.6 \times 10^{-3}$ and false-discovery rate (FDR) adjusted $p$-value $<0.05$ ).

Associations between SNP rs6687758 and risk of colorectal cancer according to general alcohol consumption status and alcohol consumption levels are shown in Table 4. In the additive model, the G allele of rs6687758 was associated with increased risk of colorectal cancer $(\mathrm{OR}=1.20,95 \% \mathrm{CI}=1.02-1.42)$. When stratified by alcohol consumption levels, risk of colorectal cancer associated with the $\mathrm{G}$ allele of rs6687758 increased among individuals who were ever or higher-level drinkers. The association between rs6687758 and colorectal cancer risk was statistically significant among ever $(\mathrm{OR}=1.35$, $95 \% \mathrm{CI}=1.11-1.64)$, moderate $(\mathrm{OR}=1.46,95 \% \mathrm{CI}=1.01$ 2.11), and higher-level drinkers in the above-the-median group $(\mathrm{OR}=1.52,95 \% \mathrm{CI}=1.14-2.04)$ and the highest 
Table 1: Characteristics of colorectal cancer cases and controls, National Cancer Center of Korea, 2010-2013

\begin{tabular}{|c|c|c|c|c|c|}
\hline \multirow[t]{3}{*}{ Characteristics } & \multirow{2}{*}{\multicolumn{2}{|c|}{$\begin{array}{c}\text { Cases } \\
(\mathrm{N}=703)\end{array}$}} & \multirow{2}{*}{\multicolumn{2}{|c|}{$\begin{array}{c}\text { Controls } \\
(\mathrm{N}=1,406)\end{array}$}} & \multirow[t]{3}{*}{$P^{\mathrm{a}}$} \\
\hline & & & & & \\
\hline & $\mathbf{N}$ & $(\%)$ & $\mathbf{N}$ & $(\%)$ & \\
\hline Age (years), mean (SD) & 56.4 & $(9.6)$ & 56.0 & $(9.1)$ & 0.31 \\
\hline \multicolumn{5}{|l|}{ Sex } & $>0.99$ \\
\hline Men & 480 & $(68.3)$ & 960 & $(68.3)$ & \\
\hline Women & 223 & $(31.7)$ & 446 & $(31.7)$ & \\
\hline \multicolumn{5}{|c|}{ Family history of colorectal cancer } & 0.01 \\
\hline No & 638 & $(90.8)$ & 1,319 & $(93.8)$ & \\
\hline Yes & 65 & $(9.3)$ & 87 & $(6.2)$ & \\
\hline BMI $\left(\mathrm{kg} / \mathrm{m}^{2}\right)$, mean $(\mathrm{SD})$ & 23.8 & (3.4) & 24.1 & $(2.7)$ & 0.04 \\
\hline \multicolumn{5}{|l|}{ Education level } & $<0.01$ \\
\hline$\leq$ Middle school & 255 & $(36.3)$ & 197 & $(14.0)$ & \\
\hline$\leq$ High school & 269 & $(38.3)$ & 457 & $(32.5)$ & \\
\hline$\geq$ College or university & 179 & $(25.5)$ & 741 & $(52.7)$ & \\
\hline \multicolumn{5}{|l|}{ Marital status } & $<0.01$ \\
\hline Married & 595 & $(84.6)$ & 1,268 & $(90.2)$ & \\
\hline Unmarried $^{\mathrm{b}}$ & 106 & $(15.1)$ & 134 & $(9.5)$ & \\
\hline \multicolumn{5}{|l|}{ Alcohol consumption status } & 0.50 \\
\hline Never & 210 & $(29.9)$ & 400 & $(28.5)$ & \\
\hline Ever & 493 & $(70.1)$ & 1,006 & $(71.6)$ & \\
\hline \multicolumn{5}{|l|}{ Smoking status } & 0.64 \\
\hline Never & 316 & $(45.0)$ & 617 & $(45.0)$ & \\
\hline Ever & 387 & $(55.1)$ & 789 & $(55.1)$ & \\
\hline \multicolumn{5}{|l|}{ Regular exercise participation } & $<0.01$ \\
\hline No & 474 & $(67.4)$ & 566 & $(40.3)$ & \\
\hline Yes & 229 & $(32.6)$ & 833 & $(59.3)$ & \\
\hline
\end{tabular}

Abbreviations: SD (standard deviation) and BMI (body mass index).

${ }^{a}$ T-test for continuous variables and chi-square test for categorical variables.

${ }^{b}$ Unmarried category includes never married, divorced, separated, and widowed individuals.

tertile of alcohol consumption $(\mathrm{OR}=1.59,95 \% \mathrm{CI}=1.12$ 2.25). After stratification by sex, no GEIs were observed between rs6687758 and alcohol consumption, and the statistically significant association between rs6687758 and colorectal cancer risk among ever or higher-level alcohol drinkers remained only among men (Supplementary Table 3). Although a GEI between rs 4813802 and alcohol consumption based on standardized drink amounts was observed, the association between rs4813802 and colorectal cancer risk was not statistically significant regardless of alcohol consumption level (data not shown).

\section{DISCUSSION}

In this case-control study, we investigated possible interactions between GWAS-identified colorectal cancer susceptibility SNPs and alcohol consumption. We observed that higher levels of alcohol consumption and the risk allele (G) of the SNP rs6687758 had statistically significant associations with increased risk of colorectal cancer. Furthermore, rs6687758 showed a consistent interaction with alcohol consumption and colorectal cancer and was associated with increased risk of colorectal 
Table 2: Associations between alcohol consumption and colorectal cancer risk

\begin{tabular}{|c|c|c|c|c|c|c|}
\hline \multirow[t]{3}{*}{ Alcohol consumption } & \multirow{2}{*}{\multicolumn{2}{|c|}{$\begin{array}{c}\text { Case } \\
(N=703)\end{array}$}} & \multirow{2}{*}{\multicolumn{2}{|c|}{$\begin{array}{c}\text { Control } \\
(\mathrm{N}=1,406)\end{array}$}} & \multirow[t]{3}{*}{$\mathbf{O R}^{\mathbf{a}}$} & \multirow[t]{3}{*}{$(95 \% \mathrm{CI})$} \\
\hline & & & & & & \\
\hline & $\mathbf{N}$ & $(\%)$ & $\mathbf{N}$ & $(\%)$ & & \\
\hline \multicolumn{7}{|l|}{ General alcohol consumption status } \\
\hline Never & 210 & $(29.9)$ & 400 & $(28.5)$ & 1.00 & (ref.) \\
\hline Ever & 493 & $(70.1)$ & 1006 & $(71.6)$ & 1.04 & $(0.81-1.33)$ \\
\hline \multicolumn{7}{|c|}{ Alcohol consumption by standardized drink amounts ( $\mathrm{g} /$ day) } \\
\hline Never & 210 & $(32.3)$ & 400 & $(30.2)$ & 1.00 & (ref.) \\
\hline Light $(\leq 12.5)$ & 186 & $(28.6)$ & 530 & $(40.0)$ & 0.84 & $(0.64-1.11)$ \\
\hline Moderate $(>12.5$ and $\leq 50)$ & 153 & $(23.5)$ & 324 & $(24.4)$ & 1.10 & $(0.80-1.52)$ \\
\hline Heavy $(>50)$ & 102 & $(15.7)$ & 72 & $(5.4)$ & 2.47 & $(1.62-3.76)$ \\
\hline$P$ for trend & & & & $<0.01$ & & \\
\hline \multicolumn{7}{|c|}{ Alcohol consumption by median intake ( $\mathrm{g} /$ day) } \\
\hline Never & 210 & $(32.3)$ & 400 & $(30.2)$ & 1.00 & (ref.) \\
\hline Equal to or below median $(\leq 11.5)$ & 175 & $(26.9)$ & 506 & $(38.2)$ & 0.84 & $(0.64-1.10)$ \\
\hline Above median $(>11.5)$ & 266 & $(40.9)$ & 420 & $(31.7)$ & 1.33 & $(0.99-1.80)$ \\
\hline$P$ for trend & & & & 0.05 & & \\
\hline \multicolumn{7}{|c|}{ Alcohol consumption by tertiles of intake (g/day) } \\
\hline Never & 210 & $(32.3)$ & 400 & $(30.2)$ & 1.00 & (ref.) \\
\hline 1st tertile $(\leq 5.6)$ & 111 & $(17.1)$ & 346 & $(26.1)$ & 0.78 & $(0.58-1.05)$ \\
\hline 2nd tertile $(>5.6$ and $\leq 21.8)$ & 138 & $(21.2)$ & 316 & $(23.8)$ & 1.07 & $(0.77-1.50)$ \\
\hline 3rd tertile $(>21.8)$ & 192 & $(29.5)$ & 264 & $(19.9)$ & 1.50 & $(1.08-2.07)$ \\
\hline$P$ for trend & & & & $<0.01$ & & \\
\hline
\end{tabular}

Abbreviations: OR (odds ratio), CI (confidence interval), and BMI (body mass index).

${ }^{a}$ Logistic regression model adjusted for age, sex, family history of colorectal cancer, BMI, education level, marital status, smoking status, and regular exercise.

cancer among ever and higher-level alcohol drinkers, suggesting that alcohol consumption could be a possible effect modifier.

Although previous GWAS have discovered common susceptibility SNPs associated with colorectal cancer risk, those SNPs explain only a small proportion (1-4\%) of the genetic heritability of colorectal cancer, suggesting that a considerable amount of heritability remains unaccounted for [10]. We analyzed post-GWAS GEIs to investigate the missing heritability [11]. To date, GEI studies have been limited mainly to candidate genes and specific environmental factors. Therefore, we focused on GWAS-identified colorectal cancer-susceptibility SNPs that had been robustly replicated and that were relatively unstudied with respect to GEI in order to discover novel GEI and achieve better insights into the biological mechanisms underlying colorectal cancer.
A number of studies have evaluated whether variants of candidate genes involved in alcohol metabolism interact with alcohol consumption and colorectal cancer; however, the results have been inconsistent. Several studies have found statistically significant interactions of variants in the $A D H 1 B$ [12], ALDH2 [13], CYP2E1 [13, 14], and $M T H F R$ [15-18] genes with alcohol consumption and colorectal cancer, whereas other studies found no interactions with $A D H 1 B$ [19], $A D H 1 C$ [19, 20], ADH7 [12], ALDH2 [12, 19, 21, 22], and MTHFR [23-26] variants. Besides alcohol-metabolism related genes, interactions with alcohol consumption have been reported in polymorphisms of the PTEN [27], XPA [28], XPC [28], $X P D$ [28], GPX1 [29], NQO1 [30, 31], PPAR [32], MTR [33], XRCC1 [34] genes, but no interactions have been reported for polymorphisms in the $O G G 1$ [29] or XRCC1 
Table 3: $\boldsymbol{P}$-value for the effect of interaction between GWAS-identified SNPs and alcohol consumption by standardized drink amounts on risk of colorectal cancer

\begin{tabular}{|c|c|c|c|c|c|c|}
\hline \multirow[t]{2}{*}{ SNP } & \multirow[t]{2}{*}{ Cytogenetic region } & \multirow[t]{2}{*}{ Mapped gene } & \multicolumn{2}{|c|}{ Allele $^{a}$} & \multicolumn{2}{|c|}{$\begin{array}{l}\text { Alcohol consumption by standardized drink } \\
\text { amounts (never, light, moderate, heavy) }\end{array}$} \\
\hline & & & A1 & A2 & $\operatorname{Raw} p^{\mathrm{b}}$ & FDR-adjusted $p$ \\
\hline rs6687758 & $1 \mathrm{q} 41$ & intergenic & $\mathrm{G}$ & $\mathrm{A}$ & $4.6 \times 10^{-3}$ & 0.14 \\
\hline rs10936599 & $3 \mathrm{q} 26.2$ & $M Y N N$ & $\mathrm{~T}$ & $\mathrm{C}$ & 0.35 & 0.80 \\
\hline rs647161 & $5 q 31.1$ & C5orf66 & A & $\mathrm{C}$ & 0.79 & 0.94 \\
\hline rs7758229 & $6 \mathrm{q} 25.3$ & $S L C 22 A 3$ & $\mathrm{~T}$ & $\mathrm{G}$ & 0.90 & 0.94 \\
\hline rs6983267 & $8 \mathrm{q} 24.21$ & CASC8, CCAT2 & $\mathrm{T}$ & G & 0.26 & 0.80 \\
\hline rs7014346 & $8 \mathrm{q} 24.21$ & CASC 8 & $\mathrm{G}$ & A & 0.33 & 0.80 \\
\hline rs 10505477 & $8 \mathrm{q} 24.21$ & CASC8 & $\mathrm{G}$ & A & 0.34 & 0.80 \\
\hline rs 10795668 & $10 \mathrm{p} 14$ & LOC105376400 & A & $\mathrm{G}$ & 0.43 & 0.80 \\
\hline rs 704017 & $10 \mathrm{q} 22.3$ & ZMIZ1-AS1 & G & A & 0.38 & 0.80 \\
\hline rs11196172 & $10 \mathrm{q} 25.2$ & TCF7L2 & A & $\mathrm{G}$ & 0.21 & 0.80 \\
\hline rs 1665650 & $10 \mathrm{q} 25.3$ & HSPA12A & $\mathrm{C}$ & $\mathrm{T}$ & 0.50 & 0.84 \\
\hline rs 174537 & $11 \mathrm{q} 12.2$ & MYRF & $\mathrm{T}$ & $\mathrm{G}$ & 0.67 & 0.84 \\
\hline rs 174550 & $11 \mathrm{q} 12.2$ & FADS1 & $\mathrm{T}$ & $\mathrm{C}$ & 0.64 & 0.84 \\
\hline rs 1535 & $11 \mathrm{q} 12.2$ & FADS2 & A & G & 0.64 & 0.84 \\
\hline rs 3802842 & $11 \mathrm{q} 23.1$ & $\begin{array}{l}\text { COLCA1, } \\
\text { COLCA2 }\end{array}$ & A & $\mathrm{C}$ & 0.14 & 0.80 \\
\hline rs 10849432 & $12 \mathrm{p} 13.31$ & intergenic & $\mathrm{T}$ & $\mathrm{C}$ & 0.42 & 0.80 \\
\hline rs 10774214 & $12 \mathrm{p} 13.32$ & $C C N D 2-A S 1$ & $\mathrm{C}$ & $\mathrm{T}$ & 0.24 & 0.80 \\
\hline rs11169552 & $12 q 13.12$ & $\begin{array}{c}\text { ATF1, } \\
\text { LOC105369765 }\end{array}$ & $\mathrm{T}$ & $\mathrm{C}$ & 0.85 & 0.94 \\
\hline rs7136702 & $12 q 13.13$ & intergenic & $\mathrm{C}$ & $\mathrm{T}$ & 0.62 & 0.84 \\
\hline rs4444235 & $14 q 22.2$ & intergenic & $\mathrm{C}$ & $\mathrm{T}$ & 0.67 & 0.84 \\
\hline rs 1957636 & $14 \mathrm{q} 22.3$ & LOC105370507 & $\mathrm{C}$ & $\mathrm{T}$ & 0.98 & 0.98 \\
\hline rs4779584 & $15 q 13.3$ & intergenic & $\mathrm{C}$ & $\mathrm{T}$ & 0.24 & 0.80 \\
\hline rs9929218 & $16 \mathrm{q} 22.1$ & $\mathrm{CDH1}$ & A & $\mathrm{G}$ & 0.50 & 0.84 \\
\hline rs 12603526 & $17 \mathrm{p} 13.3$ & intergenic & $\mathrm{C}$ & $\mathrm{T}$ & 0.89 & 0.94 \\
\hline rs 10411210 & $19 \mathrm{q} 13.11$ & RHPN2 & $\mathrm{T}$ & $\mathrm{C}$ & 0.40 & 0.80 \\
\hline rs 1800469 & $19 \mathrm{q} 13.2$ & B9D2, TGFB1 & $\mathrm{G}$ & A & 0.25 & 0.80 \\
\hline rs2241714 & $19 \mathrm{q} 13.2$ & $\begin{array}{l}\text { B9D2, } \\
\text { TMEM91 }\end{array}$ & $\mathrm{C}$ & $\mathrm{T}$ & 0.40 & 0.80 \\
\hline rs 961253 & $20 \mathrm{p} 12.3$ & intergenic & A & $\mathrm{C}$ & 0.56 & 0.84 \\
\hline rs4813802 & $20 \mathrm{p} 12.3$ & intergenic & G & $\mathrm{T}$ & 0.02 & 0.31 \\
\hline rs2423279 & $20 \mathrm{p} 12.3$ & intergenic & $\mathrm{C}$ & $\mathrm{T}$ & 0.83 & 0.94 \\
\hline
\end{tabular}

Abbreviations: GWAS (genome-wide association study), SNP (single-nucleotide polymorphism), FDR (false-discovery rate), SNP (single-nucleotide polymorphism), and BMI (body mass index).

${ }^{\mathrm{a}} \mathrm{A} 1$ is the risk and $\mathrm{A} 2$ is the reference allele according to NCBI dbSNP.

${ }^{b}$ Logistic regression model including interaction term (additive genotypes for each SNP $\times$ alcohol consumption) adjusted for age, sex, family history of colorectal cancer, BMI, education level, marital status, smoking status, and regular exercise. 
Table 4: Associations between additive risk allele of rs6687758 and risk of colorectal cancer stratified by alcohol consumption

\begin{tabular}{|c|c|c|c|c|c|}
\hline \multirow[t]{2}{*}{ Alcohol consumption } & \multicolumn{2}{|c|}{ RAF } & \multirow[t]{2}{*}{$\mathbf{O R}^{\mathrm{a}}$} & \multirow[t]{2}{*}{$(95 \% \mathrm{CI})$} & \multirow[t]{2}{*}{$P_{\text {interaction }}$} \\
\hline & Case & Control & & & \\
\hline \multicolumn{6}{|c|}{ rs6687758 (1q41/intergenic, $\left.\mathrm{G} / \mathrm{A}^{\mathrm{c}}\right)$} \\
\hline All & 0.30 & 0.27 & 1.20 & $(1.02-1.42)$ & - \\
\hline General alcohol consumption status & & & & & 0.02 \\
\hline Never & 0.29 & 0.27 & 0.90 & $(0.65-1.24)$ & \\
\hline Ever & 0.31 & 0.27 & 1.35 & $(1.11-1.64)$ & \\
\hline \multicolumn{5}{|c|}{ Alcohol consumption by standardized drink amounts (g/day) } & $4.6 \times 10^{-3}$ \\
\hline Never & 0.29 & 0.27 & 0.90 & $(0.65-1.24)$ & \\
\hline Light $(\leq 12.5)$ & 0.29 & 0.26 & 1.26 & $(0.93-1.70)$ & \\
\hline Moderate $(>12.5$ and $\leq 50)$ & 0.32 & 0.26 & 1.46 & $(1.01-2.11)$ & \\
\hline Heavy $(>50)$ & 0.31 & 0.24 & 1.71 & $(0.94-3.14)$ & \\
\hline \multicolumn{5}{|c|}{ Alcohol consumption by median intake (g/day) } & $7.4 \times 10^{-3}$ \\
\hline Never & 0.29 & 0.27 & 0.90 & $(0.65-1.24)$ & \\
\hline Equal to or below median $(\leq 11.5)$ & 0.30 & 0.26 & 1.26 & $(0.92-1.71)$ & \\
\hline Above median $(>11.5)$ & 0.31 & 0.26 & 1.52 & $(1.14-2.04)$ & \\
\hline \multicolumn{5}{|c|}{ Alcohol consumption by tertiles of intake (g/day) } & $3.9 \times 10^{-3}$ \\
\hline Never & 0.29 & 0.27 & 0.90 & $(0.65-1.24)$ & \\
\hline 1 st tertile $(\leq 5.6)$ & 0.29 & 0.27 & 1.14 & $(0.77-1.70)$ & \\
\hline 2nd tertile $(>5.6$ and $\leq 21.8)$ & 0.30 & 0.26 & 1.42 & $(0.98-2.06)$ & \\
\hline 3rd tertile $(>21.8)$ & 0.32 & 0.25 & 1.59 & $(1.12-2.25)$ & \\
\hline
\end{tabular}

Abbreviations: SNP (single-nucleotide polymorphism), RAF (risk allele frequency), OR (odds ratio), CI (confidence interval), BMI (body mass index).

${ }^{a}$ Additive effect by logistic regression model adjusted for age, sex, family history of colorectal cancer, BMI, education level, marital status, smoking status, and regular exercise by alcohol consumption.

${ }^{\mathrm{b}}$ Logistic regression model including interaction term (additive genotypes for $\mathrm{rs} 6687758 \times$ alcohol consumption).

${ }^{c}$ Risk/reference allele according to NCBI dbSNP.

[35] genes or for haplotypes of $A S E-1, R A I$, and $E R C C 1$ polymorphisms [36].

A few studies have investigated known colorectal cancer-susceptibility SNPs discovered by GWAS or have conducted a gene-environment-wide interaction study (GEWIS) for possible GEIs related to alcohol consumption and colorectal cancer. One study discovered that SNP rs9929218 at 16q22.1 (CDH1) showed an interaction with alcohol consumption in the screening phase, but failed to replicate [5]. Another study reported nominally significant GEIs with alcohol consumption for rs16892766 at 8q23.3 (EIF3H), rs719725 at 9p24.1 (UHRF2), and rs9929218 at 16q22.1 (CDH1) in a caseonly analysis and in rs3802842 in both case-only and case-control analyses [6]. However, other studies have found no evidence for GEIs for known colorectal cancer- susceptibility SNPs with alcohol consumption and colorectal cancer [7-9]. On the other hand, a previous GEWIS reported that interactions of rs12870649 at 13q14.1 (CTNNA3) and rs9409565 at 9q22.32 (HIATL1) with alcohol consumption were associated with colorectal cancer risk $[6,37]$.

In our analyses, the effects of interactions between SNP rs6687758 and alcohol consumption on colorectal cancer risk were consistently statistically significant regardless of general alcohol consumption status or alcohol consumption level. Rs6687758 was associated with colorectal cancer risk in Europeans [38] as well as in East Asians [39]. We were able to replicate the association between rs6687758 and colorectal cancer risk in our East Asian study population with the same/expected direction of association as the prior study. However, another European- 
population study tested GEIs between rs6687758 and alcohol consumption and they found no statistically significant result [9]. These deviations may be caused by ethnic differences (European vs. Asian populations) in the type of alcoholic beverages consumed, genetic factors involved in alcohol metabolism and sensitivity, or potential interaction with different environmental factors. In addition, in the European-population study the alcohol variable was categorized as $<1,1$ to $<28$, and $\geq 28 \mathrm{~g} /$ day due to the multistep harmonization required to combine data across diverse studies, whereas our study categorized it based on standardized drink amounts, as well as by the median and tertiles of intake.

SNP rs6687758 is located in an intergenic region on chromosome 1q41. Rs6687758 lies $125 \mathrm{~kb}$ upstream of the DUSP10 gene, which encodes dual-specificity phosphatase 10 (DUSP10, also known as mitogenactivated protein kinase (MAPK) phosphatase 5 (MKP5)). DUSP10 inactivates other MAPKs, such as extracellular signal-regulated kinase 1/2 (ERK1/2), p38, and c-Jun $\mathrm{N}$-terminal protein kinase (JNK), which are involved in cellular proliferation and differentiation, enhancing the progression of colorectal cancer [40]. However, the inhibition of p38 and JNK activation was attenuated by alcohol-induced cellular responses, including cell migration and invasion [41], and p38 MAPK signaling including DUSP10 expression has been reported to be significantly altered in the hippocampus of chronic alcoholics [42]. This finding may imply that DUSP10 is a tumor suppressor and may be modified by alcohol consumption.

In our study, none of the GEI effects of the 30 GWAS-identified colorectal cancer-susceptibility SNPs with alcohol consumption and colorectal cancer risk remained statistically significant, after accounting for multiple comparisons (i.e., $p$-value for Bonferroni correction $<1.6 \times 10^{-3}$ and false-discovery rate (FDR) adjusted $p$-value $<0.05)$. Furthermore, the GEI between rs6687758 and alcohol consumption was not statistically significant in additional case-only analysis and replication study could not be conducted for the finding. This may be because there were no true interactions between the genetic and environmental factors under study. However, when we conducted an internal cross-validation, the estimated area under the receiver operating characteristic (ROC) curve (AUC) values were 0.74 for the original model and 0.73 for the validation model. This indicated a bias in the $\mathrm{C}$ statistic of approximately $1 \%$ and, thus, an acceptable model performance. Furthermore, SNP rs6687758 showed a consistent interaction with alcohol consumption, irrespective of general alcohol consumption status or alcohol consumption level whether assessed by standardized drink amounts, by the intake median, or by tertiles of intake, indicating that the finding is unlikely to be changed by analyzing alcohol consumption as a continuous variable.
Another reason for the failure to find interactions after multiple testing could be that the study was underpowered to detect potential GEIs due to its relatively small sample size. For a similar reason, the OR for the association between rs6687758 and colorectal cancer risk among heavy drinkers was not statistically significant. In the additive model, when the genetic OR was set to 1.20 for the G allele of SNP rs6687758, the environmental OR was set to 1.04 for ever drinking status, the minor allele frequency (MAF) was set to 0.20 , and the prevalence of ever-drinker status was set to 0.71 , we had $32-62 \%$ power to detect an OR of 1.3-1.5 for GEIs at a 5\% significance level. To achieve $80 \%$ power, more than 1,069 cases would be required to detect an OR of 1.5 for GEIs under the same settings. In order to alleviate the power problem and identify potential GEIs on colorectal cancer risk, we relaxed the threshold for statistical significance without correction for multiple comparisons.

There are several strengths in this study. All study participants were recruited from the same hospital and treated as uniformly as possible with the same study protocol related to data and blood sample collection in order to minimize systematic errors caused by bias from the selection of the study population or procedures for gathering genetic and environmental data. Moreover, the entire study population was Korean and thus had an ethnically homogenous genetic background, which should reduce bias caused by population stratification. The novel possible GEI of SNP rs6687758 with alcohol consumption in colorectal cancer needs further study with a larger sample size and/or in other ethnicities to validate the findings.

In conclusion, this study observed a novel possible GEI of SNP rs6687758 and alcohol consumption with colorectal cancer risk. The results indicated that the risk allele $(\mathrm{G})$ consistently increased colorectal cancer risk among ever and heavy alcohol drinkers. Our finding suggests that alcohol consumption may strengthen the genetic effects of rs6687758 on risk of colorectal cancer.

\section{MATERIALS AND METHODS}

\section{Study population}

This hospital-based case-control study was conducted by the Korean National Cancer Center (NCC), as previously described in detail $[43,44]$. Briefly, among 1,427 eligible colorectal cancer patients who had been histologically confirmed and had given informed consent to participate in the study between 2010 and 2013, 703 patients were included in the study after applying the following exclusion criteria: failure to contact $(\mathrm{N}=168)$, patient refusal to participate after the recruitment $(\mathrm{N}=189)$, and incomplete questionnaires and/or insufficient blood samples for 
genotyping $(\mathrm{N}=367)$. Controls were recruited from among healthy individuals who visited a cancer-screening center at the same hospital for a health check-up supported by the National Health Insurance Corporation between 2007 and 2014. After applying the same exclusion criteria above, cases and controls were 1:2 frequency-matched for age (5-year intervals) and sex, leaving a total of 703 colorectal cancer cases and 1,406 controls for the analysis. The study was approved by the institutional review board of the NCC (IRB No. NCCNCS-10-350 and NCC 2015-0202).

\section{Data collection}

At enrollment, face-to-face interviews were conducted by trained interviewers with colorectal cancer cases by using a structured written questionnaire. Controls were asked to complete a self-administered questionnaire and were called by interviewers to confirm the responses, as detailed elsewhere [43, 44]. The questionnaire collected general and lifestyle information regarding family history of colorectal cancer, education level, marital status, and alcohol drinking, smoking, and regular exercise habits. BMI $\left(\mathrm{kg} / \mathrm{m}^{2}\right)$ was calculated based on weight $(\mathrm{kg})$ and height $(\mathrm{m})$ measured during a physical examination.

\section{Assessment of alcohol consumption}

The collected alcohol consumption information consisted of drinking status (never or ever), usual frequency at which alcohol was consumed (1/month, 2-3/month, 1/ week, 2-3/week, 4-6/week, 1/day, and 2/day), the average number of drinks consumed per drinking occasion by type of alcoholic beverage, specifically beer, soju (a Korean distilled spirit), hard liquor, makgeolli (a traditional Korean rice wine), wine, and other fruit wines. The Korean Genome and Epidemiology Study standardized a single drink of alcohol for the the Korean population as follows: $200 \mathrm{ml}$ of $4.5 \%$ beer, $50 \mathrm{ml}$ of $22 \%$ soju and other fruit wines, $30 \mathrm{ml}$ of $40 \%$ hard liquor, $240 \mathrm{ml}$ of $6 \%$ makgeolli, and $90 \mathrm{ml}$ of $13 \%$ general wine, which contained $7.90 \mathrm{~g}, 8.78 \mathrm{~g}, 9.58 \mathrm{~g}$, $11.50 \mathrm{~g}$, and $9.34 \mathrm{~g}$ of ethanol, respectively, based on the density of ethanol $(0.79 \mathrm{~g} / \mathrm{ml})$ [45]. The total amount of daily alcohol consumption (g/day) was assessed by summing each beverage-specific amount, which was calculated by multiplying the daily frequency, the number of drinks, and the ethanol content. Alcohol consumption was then categorized as light $(\leq 12.5 \mathrm{~g} /$ day $)$, moderate $(>12.5$ and $\leq 50.0 \mathrm{~g} /$ day $)$, or heavy $(>50 \mathrm{~g} /$ day $)$ based on standardized drink amounts where 1 drink $=12.5 \mathrm{~g}$ of ethanol [46] or by the median or tertiles of intake.

\section{SNP selection and genotyping}

As described in detail elsewhere [44], we selected 36 colorectal cancer susceptibility SNPs by reviewing previously published GWAS [38, 39, 47-55]. Genomic DNA was extracted by using a MagAttract DNA Blood
M48 kit and BioRobot M48 automatic extraction equipment (Qiagen, Hilden, Germany) and genotyping was performed by using an Agenabio MassArray iPLEX ${ }^{\circledR}$ gold assay (Agena Bioscience, Inc., San Diego, California, United States). In brief, from among 36 originally selected SNPs, a total of 30 colorectal cancersusceptibility SNPs were included the analysis after exclusion of 4 SNPs that failed to genotype and 2 SNPs that were monomorphic.

\section{Statistical analysis}

For each SNP, the Hardy-Weinberg equilibrium (HWE) test was conducted using the chi-square test among controls, as previously reported [44]. We compared 703 colorectal cancer cases and 1,406 healthy controls to test differences in characteristics using a $t$ test for continuous variables and the chi-square test for categorical variables. The association between variants of SNPs or alcohol consumption and colorectal cancer risk was estimated by using a logistic regression model adjusted for potential confounders. We selected age, sex, family history of colorectal cancer, BMI, education level, marital status, smoking status, and regular exercise that were considered to be associated with colorectal cancer risk based on the association test and literature review as the potential confounders. The full model adjusted for all potential confounders provided a better fit than the unadjusted model $(p<0.01)$. To investigate the GEIs, we additionally included a multiplicative interaction term composed of the additive genotypes of each SNP and alcohol consumption factors. For susceptibility SNPs that statistically interacted with one or more alcohol consumption factors on colorectal cancer risk, the association between SNPs and colorectal cancer risk was stratified by alcohol consumption factors to evaluate whether it played a role as an effect modifier. Hypothesis testing was performed overall and stratified by sex and estimated by OR, $95 \% \mathrm{CI}$, and $p$-values. Statistical significance was considered to be a $p$-value equal to or less than 0.05. For multiple testing, Bonferroniand FDR-adjusted $p$-values were also calculated, but the corrections were not applied because none of the associations were significant. All statistical analyses were two-sided and performed by using SAS version 9.4 software (SAS Institute, Inc., Cary, North Carolina, United States).

\section{Abbreviations}

Acetaldehyde dehydrogenase (ALDH); alcohol dehydrogenase (ADH); body mass index (BMI); confidence interval (CI); cytochrome P450 2E1 (CYP2E1); dual-specificity phosphatase 10 (DUSP10); extracellular signal-regulated kinase 1/2 (ERK1/2); false-discovery rate (FDR); gene and environment 
interaction (GEI); gene-environment-wide interaction study (GEWIS); genome-wide association studies (GWAS); Hardy-Weinberg equilibrium (HWE); c-Jun $\mathrm{N}$-terminal protein kinase (JNK); minor allele frequency (MAF); mitogen-activated protein kinase (MAPK); mitogen-activated protein kinase phosphatase 5 (MKP5); methylenetetrahydrofolate reductase (MTHFR); National Cancer Center (NCC); odds ratio (OR); single-nucleotide polymorphism (SNP).

\section{Author contributions}

NS and AS designed and conducted the study and interpreted the findings. NS reviewed the literature, performed the data analysis, and wrote the manuscript. JHO conducted the data and sample collection. AS and JK contributed to the supervision of the study. All authors critically reviewed and approved the final version of the manuscript.

\section{CONFLICTS OF INTEREST}

There are no conflicts of interest to disclose.

\section{FUNDING}

This research was supported by the Basic Science Research Program through the National Research Foundation of Korea (2009-0093820, 2010-0010276, 2013R1A1A2A10008260) and the National Cancer Center of Korea (0910220, 1210141). This manuscript was edited by Ms. Bethanie Rammer, BioMedEdits.com, for clarity, consistency, and English-language usage.

\section{REFERENCES}

1. Cogliano VJ, Baan R, Straif K, Grosse Y, Lauby-Secretan B, El Ghissassi F, Bouvard V, Benbrahim-Tallaa L, Guha N, Freeman C, Galichet L, Wild CP. Preventable exposures associated with human cancers. J Natl Cancer Inst. 2011; 103:1827-1839.

2. Seitz HK, Stickel F. Molecular mechanisms of alcoholmediated carcinogenesis. Nat Rev Cancer. 2007; 7:599-612.

3. Keum N, Giovannucci EL. (2017). Epidemiology of colorectal cancer. Pathology and Epidemiology of Cancer: Springer, pp. 391-407.

4. Druesne-Pecollo N, Tehard B, Mallet Y, Gerber M, Norat T, Hercberg S, Latino-Martel P. Alcohol and genetic polymorphisms: effect on risk of alcohol-related cancer. Lancet Oncol. 2009; 10:173-180.

5. Figueiredo JC, Lewinger JP, Song C, Campbell PT, Conti DV, Edlund CK, Duggan DJ, Rangrej J, Lemire M, Hudson T, Zanke B, Cotterchio M, Gallinger S, et al. Genotype-environment interactions in microsatellite stable/ microsatellite instability-low colorectal cancer: results from a genome-wide association study. Cancer Epidemiol Biomarkers Prev. 2011; 20:758-766.

6. Siegert S, Hampe J, Schafmayer C, von Schonfels W, Egberts JH, Forsti A, Chen B, Lascorz J, Hemminki K, Franke A, Nothnagel M, Nothlings U, Krawczak M, et al. Genome-wide investigation of gene-environment interactions in colorectal cancer. Hum Genet. 2013; 132:219-231.

7. Hutter CM, Chang-Claude J, Slattery ML, Pflugeisen BM, Lin Y, Duggan D, Nan H, Lemire M, Rangrej J, Figueiredo JC, Jiao S, Harrison TA, Liu Y, et al. Characterization of gene-environment interactions for colorectal cancer susceptibility loci. Cancer Res. 2012; 72:2036-2044.

8. Kocarnik JD, Hutter CM, Slattery ML, Berndt SI, Hsu L, Duggan DJ, Muehling J, Caan BJ, Beresford SA, Rajkovic A, Sarto GE, Marshall JR, Hammad N, et al. Characterization of 9p24 risk locus and colorectal adenoma and cancer: gene-environment interaction and meta-analysis. Cancer Epidemiol Biomarkers Prev. 2010; 19:3131-3139.

9. Kantor ED, Hutter CM, Minnier J, Berndt SI, Brenner H, Caan BJ, Campbell PT, Carlson CS, Casey G, Chan AT, Chang-Claude J, Chanock SJ, Cotterchio M, et al. Geneenvironment interaction involving recently identified colorectal cancer susceptibility Loci. Cancer Epidemiol Biomarkers Prev. 2014; 23:1824-1833.

10. Peters U, Bien S, Zubair N. Genetic architecture of colorectal cancer. Gut. 2015.

11. Ober C, Vercelli D. Gene-environment interactions in human disease: nuisance or opportunity? Trends Genet. 2011; 27:107-115.

12. Ferrari P, McKay JD, Jenab M, Brennan P, Canzian F, Vogel U, Tjonneland A, Overvad K, Tolstrup JS, BoutronRuault MC, Clavel-Chapelon F, Morois S, Kaaks R, et al. Alcohol dehydrogenase and aldehyde dehydrogenase gene polymorphisms, alcohol intake and the risk of colorectal cancer in the European Prospective Investigation into Cancer and Nutrition study. Eur J Clin Nutr. 2012; 66:1303-1308.

13. Yang H, Zhou Y, Zhou Z, Liu J, Yuan X, Matsuo K, Takezaki T, Tajima K, Cao J. A novel polymorphism rs1329149 of CYP2E1 and a known polymorphism rs671 of ALDH2 of alcohol metabolizing enzymes are associated with colorectal cancer in a southwestern Chinese population. Cancer Epidemiol Biomarkers Prev. 2009; 18:2522-2527.

14. Gao CM, Takezaki T, Wu JZ, Chen MB, Liu YT, Ding JH, Sugimura H, Cao J, Hamajima N, Tajima K. CYP2E1 Rsa I polymorphism impacts on risk of colorectal cancer association with smoking and alcohol drinking. World J Gastroenterol. 2007; 13:5725-5730.

15. Ma J, Stampfer MJ, Giovannucci E, Artigas C, Hunter DJ, Fuchs C, Willett WC, Selhub J, Hennekens CH, Rozen R. Methylenetetrahydrofolate reductase polymorphism, dietary 
interactions, and risk of colorectal cancer. Cancer Res. 1997; 57:1098-1102.

16. Chen J, Giovannucci E, Kelsey K, Rimm EB, Stampfer MJ, Colditz GA, Spiegelman D, Willett WC, Hunter DJ. A methylenetetrahydrofolate reductase polymorphism and the risk of colorectal cancer. Cancer Res. 1996; $56: 4862-4864$.

17. Matsuo K, Ito H, Wakai K, Hirose K, Saito T, Suzuki T, Kato T, Hirai T, Kanemitsu Y, Hamajima H, Tajima K. Onecarbon metabolism related gene polymorphisms interact with alcohol drinking to influence the risk of colorectal cancer in Japan. Carcinogenesis. 2005; 26:2164-2171.

18. Le Marchand L, Wilkens LR, Kolonel LN, Henderson BE. The MTHFR C677T polymorphism and colorectal cancer: the multiethnic cohort study. Cancer Epidemiol Biomarkers Prev. 2005; 14:1198-1203.

19. Yin G, Kono S, Toyomura K, Moore MA, Nagano J, Mizoue T, Mibu R, Tanaka M, Kakeji Y, Maehara Y, Okamura T, Ikejiri K, Futami K, et al. Alcohol dehydrogenase and aldehyde dehydrogenase polymorphisms and colorectal cancer: the Fukuoka Colorectal Cancer Study. Cancer Sci. 2007; 98:1248-1253.

20. Bongaerts BW, de Goeij AF, Wouters KA, van Engeland M, Gottschalk RW, Van Schooten FJ, Goldbohm RA, van den Brandt PA, Weijenberg MP. Alcohol consumption, alcohol dehydrogenase 1C (ADH1C) genotype, and risk of colorectal cancer in the Netherlands Cohort Study on diet and cancer. Alcohol. 2011; 45:217-225.

21. Murata M, Tagawa M, Watanabe S, Kimura H, Takeshita T, Morimoto K. Genotype difference of aldehyde dehydrogenase 2 gene in alcohol drinkers influences the incidence of Japanese colorectal cancer patients. Jpn J Cancer Res. 1999; 90:711-719.

22. Matsuo K, Hamajima N, Hirai T, Kato T, Koike K, Inoue M, Takezaki T, Tajima K. Aldehyde dehydrogenase 2 (ALDH2) genotype affects rectal cancer susceptibility due to alcohol consumption. J Epidemiol. 2002; 12:70-76.

23. Keku T, Millikan R, Worley K, Winkel S, Eaton A, Biscocho L, Martin C, Sandler R. 5,10-Methylenetetrahydrofolate reductase codon 677 and 1298 polymorphisms and colon cancer in African Americans and whites. Cancer Epidemiol Biomarkers Prev. 2002; 11:1611-1621.

24. Yin G, Kono S, Toyomura K, Hagiwara T, Nagano J, Mizoue T, Mibu R, Tanaka M, Kakeji Y, Maehara Y. Methylenetetrahydrofolate reductase C677T and A1298C polymorphisms and colorectal cancer: the Fukuoka Colorectal Cancer Study. Cancer Sci. 2004; 95:908-913.

25. Wang J, Gajalakshmi V, Jiang J, Kuriki K, Suzuki S, Nagaya T, Nakamura S, Akasaka S, Ishikawa H, Tokudome S. Associations between 5, 10-methylenetetrahydrofolate reductase codon 677 and 1298 genetic polymorphisms and environmental factors with reference to susceptibility to colorectal cancer: a case-control study in an Indian population. Int J Cancer. 2006; 118:991-997.
26. Kim DH, Ahn YO, Lee BH, Tsuji E, Kiyohara C, Kono S. Methylenetetrahydrofolate reductase polymorphism, alcohol intake, and risks of colon and rectal cancers in Korea. Cancer Lett. 2004; 216:199-205.

27. Han M, Wu G, Sun P, Nie J, Zhang J, Li Y. Association of genetic polymorphisms in PTEN and additional interaction with alcohol consumption and smoking on colorectal cancer in Chinese population. Int J Clin Exp Med. 2015; 8:21629-21634.

28. Hansen RD, Sorensen M, Tjonneland A, Overvad K, Wallin H, Raaschou-Nielsen O, Vogel U. XPA A23G, XPC Lys939Gln, XPD Lys751Gln and XPD Asp312Asn polymorphisms, interactions with smoking, alcohol and dietary factors, and risk of colorectal cancer. Mutat Res. 2007; 619:68-80.

29. Hansen RD, Krath BN, Frederiksen K, Tjonneland A, Overvad K, Roswall N, Loft S, Dragsted LO, Vogel U, Raaschou-Nielsen O. GPX1 Pro(198)Leu polymorphism, erythrocyte GPX activity, interaction with alcohol consumption and smoking, and risk of colorectal cancer. Mutat Res. 2009; 664:13-19.

30. Mitrou PN, Watson MA, Loktionov AS, Cardwell C, Gunter MJ, Atkin WS, Macklin CP, Cecil T, Bishop DT, Primrose J, Bingham SA. Role of NQO1C609T and EPHX1 gene polymorphisms in the association of smoking and alcohol with sporadic distal colorectal adenomas: results from the UKFSS Study. Carcinogenesis. 2007; 28:875-882.

31. Peng XE, Jiang YY, Shi XS, Hu ZJ. NQO1 609C>T polymorphism interaction with tobacco smoking and alcohol drinking increases colorectal cancer risk in a Chinese population. Gene. 2013; 521:105-110.

32. Vogel U, Christensen J, Dybdahl M, Friis S, Hansen RD, Wallin H, Nexo BA, Raaschou-Nielsen O, Andersen PS, Overvad K, Tjonneland A. Prospective study of interaction between alcohol, NSAID use and polymorphisms in genes involved in the inflammatory response in relation to risk of colorectal cancer. Mutat Res. 2007; 624:88-100.

33. Yamaji T, Iwasaki M, Sasazuki S, Sakamoto H, Yoshida T, Tsugane S. Methionine synthase A2756G polymorphism interacts with alcohol and folate intake to influence the risk of colorectal adenoma. Cancer Epidemiol Biomarkers Prev. 2009; 18:267-274.

34. Yin G, Morita M, Ohnaka K, Toyomura K, Hamajima N, Mizoue T, Ueki T, Tanaka M, Kakeji Y, Maehara Y, Okamura T, Ikejiri K, Futami K, et al. Genetic polymorphisms of XRCC1, alcohol consumption, and the risk of colorectal cancer in Japan. J Epidemiol. 2012; 22:64-71.

35. Stern MC, Conti DV, Siegmund KD, Corral R, Yuan JM, Koh WP, Yu MC. DNA repair single-nucleotide polymorphisms in colorectal cancer and their role as modifiers of the effect of cigarette smoking and alcohol in the Singapore Chinese Health Study. Cancer Epidemiol Biomarkers Prev. 2007; 16:2363-2372. 
36. Hansen RD, Sorensen M, Tjonneland A, Overvad K, Wallin H, Raaschou-Nielsen O, Vogel U. A haplotype of polymorphisms in ASE-1, RAI and ERCC1 and the effects of tobacco smoking and alcohol consumption on risk of colorectal cancer: a Danish prospective case-cohort study. BMC Cancer. 2008; 8:54.

37. Gong J, Hutter CM, Newcomb PA, Ulrich CM, Bien SA, Campbell PT, Baron JA, Berndt SI, Bezieau S, Brenner H, Casey G, Chan AT, Chang-Claude J, et al. Genome-wide interaction analyses between genetic variants and alcohol consumption and smoking for risk of colorectal cancer. PLoS Genet. 2016; 12:e1006296.

38. Houlston RS, Cheadle J, Dobbins SE, Tenesa A, Jones AM, Howarth K, Spain SL, Broderick P, Domingo E, Farrington S, Prendergast JG, Pittman AM, Theodoratou E, et al. Metaanalysis of three genome-wide association studies identifies susceptibility loci for colorectal cancer at 1q41, 3q26.2, 12q13.13 and 20q13.33. Nat Genet. 2010; 42:973-977.

39. Jia WH, Zhang B, Matsuo K, Shin A, Xiang YB, Jee SH, Kim DH, Ren Z, Cai Q, Long J, Shi J, Wen W, Yang G; Genetics and Epidemiology of Colorectal Cancer Consortium (GECCO), et al. Genome-wide association analyses in East Asians identify new susceptibility loci for colorectal cancer. Nat Genet. 2013; 45:191-196.

40. Low HB, Zhang Y. Regulatory roles of MAPK phosphatases in cancer. Immune Netw. 2016; 16:85-98.

41. Zhao M, Howard EW, Parris AB, Guo Z, Zhao Q, Yang X. Alcohol promotes migration and invasion of triple-negative breast cancer cells through activation of p38 MAPK and JNK. Mol Carcinog. 2017; 56:849-862.

42. McClintick JN, Xuei X, Tischfield JA, Goate A, Foroud T, Wetherill L, Ehringer MA, Edenberg HJ. Stress-response pathways are altered in the hippocampus of chronic alcoholics. Alcohol. 2013; 47:505-515.

43. Shin A, Lee J, Lee J, Park MS, Park JW, Park SC, Oh $\mathrm{JH}, \mathrm{Kim}$ J. Isoflavone and soyfood intake and colorectal cancer risk: a case-control study in Korea. PLoS One. 2015; 10:e0143228.

44. Song N, Shin A, Park JW, Kim J, Oh JH. Common risk variants for colorectal cancer: an evaluation of associations with age at cancer onset. Sci Rep. 2017; 7:40644.

45. Kim Y. (2014). Alcohol intake and smoking-related processed data sharing from Korean genome and epidemiology study. Public Health Weekly Report, KCDC. (http://www.cdc.go.kr/phwr: Korea Centers for Disease Control and Prevention), pp. 357-360.

46. Fedirko V, Tramacere I, Bagnardi V, Rota M, Scotti L, Islami F, Negri E, Straif K, Romieu I, La Vecchia C, Boffetta P, Jenab M. Alcohol drinking and colorectal cancer risk: an overall and dose-response meta-analysis of published studies. Ann Oncol. 2011; 22:1958-1972.
47. Cui R, Okada Y, Jang SG, Ku JL, Park JG, Kamatani Y, Hosono N, Tsunoda T, Kumar V, Tanikawa C, Kamatani N, Yamada R, Kubo M, et al. Common variant in 6q26-q27 is associated with distal colon cancer in an Asian population. Gut. 2011; 60:799-805.

48. Tomlinson I, Webb E, Carvajal-Carmona L, Broderick P, Kemp Z, Spain S, Penegar S, Chandler I, Gorman M, Wood W, Barclay E, Lubbe S, Martin L, et al. A genome-wide association scan of tag SNPs identifies a susceptibility variant for colorectal cancer at 8q24.21. Nat Genet. 2007; 39:984-988.

49. Tenesa A, Farrington SM, Prendergast JG, Porteous ME, Walker M, Haq N, Barnetson RA, Theodoratou E, Cetnarskyj R, Cartwright N, Semple C, Clark AJ, Reid FJ, et al. Genome-wide association scan identifies a colorectal cancer susceptibility locus on 11q23 and replicates risk loci at 8q24 and 18q21. Nat Genet. 2008; 40:631-637.

50. Zanke BW, Greenwood CM, Rangrej J, Kustra R, Tenesa A, Farrington SM, Prendergast J, Olschwang S, Chiang T, Crowdy E, Ferretti V, Laflamme P, Sundararajan S, et al. Genome-wide association scan identifies a colorectal cancer susceptibility locus on chromosome 8q24. Nat Genet. 2007; 39:989-994.

51. Jaeger E, Webb E, Howarth K, Carvajal-Carmona L, Rowan A, Broderick P, Walther A, Spain S, Pittman A, Kemp Z, Sullivan K, Heinimann K, Lubbe S, et al. Common genetic variants at the CRAC1 (HMPS) locus on chromosome 15q13.3 influence colorectal cancer risk. Nat Genet. 2008; 40:26-28.

52. Zhang B, Jia WH, Matsuda K, Kweon SS, Matsuo K, Xiang YB, Shin A, Jee SH, Kim DH, Cai Q, Long J, Shi J, Wen W, et al. Large-scale genetic study in East Asians identifies six new loci associated with colorectal cancer risk. Nat Genet. 2014; 46:533-542.

53. Jiao S, Hsu L, Berndt S, Bezieau S, Brenner H, Buchanan D, Caan BJ, Campbell PT, Carlson CS, Casey G, Chan AT, Chang-Claude J, Chanock S, et al. Genome-wide search for gene-gene interactions in colorectal cancer. PLoS One. 2012; 7:e52535.

54. Study C, Houlston RS, Webb E, Broderick P, Pittman AM, Di Bernardo MC, Lubbe S, Chandler I, Vijayakrishnan J, Sullivan K, Penegar S; Colorectal Cancer Association Study Consortium, Carvajal-Carmona L, et al. Meta-analysis of genome-wide association data identifies four new susceptibility loci for colorectal cancer. Nat Genet. 2008; 40:1426-1435.

55. Peters U, Jiao S, Schumacher FR, Hutter CM, Aragaki AK, Baron JA, Berndt SI, Bezieau S, Brenner H, Butterbach K, Caan BJ, Campbell PT, Carlson CS, et al. Identification of genetic susceptibility loci for colorectal tumors in a genome-wide meta-analysis. Gastroenterology. 2013; 144:799-807. e724. 